\title{
Experimental Investigation of Crystalline Silica in Concrete
}

\author{
By Kasim A. Korkmaz \& Suleiman Ashur ${ }^{\dagger}$
}

\begin{abstract}
In construction industry, one of the most common materials is concrete. To increase strength and durability, various additives have been used in the industry. Crystalline Silica which has fine particles is one of these additives widely used in concrete construction. In the US, roughly 2.5 Million people are dealing with concrete in manufacturing concrete blocks, concrete cutting, or other concrete related activities such as trending, drilling, cutting, or sawing concrete. The Occupational Safety and Health Administration (OSHA) has recently stated that, Crystalline Silica in concrete is hazardous to human health. The people in risk are inhaling the silica particles and may develop silicosis, lung cancer, chronic obstructive pulmonary disease, or kidney diseases. Recently, OSHA developed new respirable crystalline silica standards for construction. With this new regulation, Crystalline Silica quantities will be limited. With this motivation, this research work deals with an experimental investigation of concrete ingredients to identify the effects of silica in construction. The paper experimentally investigates the effects of crystalline silica in concrete. The current design standards have been studied to reveal the efficiency of the silica in concrete. Compression strength and velocity tests have been used in the experimental set up. A better identification of the silica effect in concrete will help in decision process for the stakeholders in concrete industry.
\end{abstract}

Keywords: Concrete Characteristics, Concrete Mix Design, Crystalline Silica, Crystalline Silica Concentration Test.

\section{Introduction}

Concrete supplies are available in a variety of spectrum for transportation, building and other construction purposes. In the construction industry, concrete is one of the most important materials. Concrete as a material is needed for various purposes in construction regardless of the construction type. In the concrete production, cement is the most important ingredient. Besides the cement, a large amount of industrial byproduct material is in use (FHWA 2016). These byproducts include fly ash from the coal burning power plants, slag from the manufacture of iron and crystalline silica from the metal industry (ACI 224 2007, ACI 301-10 2010).

Occupational exposure to crystalline silica dust occurs is considered hazardous. Toxic chemicals, particulates and other harmful emissions in the workplace can cause significant hazards to workers. Identifying these potential hazards through research is very important to understand the solutions for such a problem. First, it should be understood what the optimum mixture is for concrete

\footnotetext{
*Assistant Professor, School of Visual and Built Environment, Eastern Michigan University, USA.

${ }^{\dagger}$ School of Visual and Built Environment, Eastern Michigan University, USA.
} 
production and how we can reduce the effects of crystalline silica on workers (OSHA 2018a). According to Occupational Safety and Health Administration (OSHA), silica exposure remains a serious threat to nearly 2 million workers, including more than 100,000 workers such as abrasive blasting, foundry work, stonecutting, rock drilling, quarry work and tunneling. The seriousness of the health hazards associated with silica exposure is demonstrated by the fatalities and disabling illnesses that continue to occur (OSHA 2018b).

With the recent research, crystalline silica has been classified as a human lung carcinogen material. Additionally, breathing crystalline silica dust can cause serious illnesses. The respirable silica dust enters the lungs and causes various diseases including tuberculosis and silicosis and currently, there is no cure for silicosis. Workers who inhale these very small crystalline silica particles are at increased risk of developing serious silica-related diseases.

OSHA has issued two new respirable crystalline silica standards: one for construction, and the other for general industry and maritime. OSHA has begun enforcing most provisions of the standard for construction on September 23, 2017 and has begun enforcing most provisions of the standard for general industry and maritime on June 23, 2018 (OSHA 2018a). Therefore, it is important to discuss the crystalline silica. This paper discusses the effects of crystalline silica in the current design on the characteristics of concrete. An experimental setup was established for the research. Velocity and compression strengths were recorded.

\section{Silica in Construction}

In construction industry, silica is in the form of combination of alkali which is considered as the concentration of concrete. When alkali is in the presence of silica hydroxyl, there is an expansion occurs, that may cause some unwanted cracks. Such issues are the main reasons for the alkali cement in low percentage is used in the presence of silica fume. Silica fume is a pozzolan material having cement properties in the wider spectrum. Silica fume acts as if it were cement because there are small particles, having silicon dioxide. Surface area can make the admixture active pozzolan if the contact area is more. ${ }^{1}$

When concrete has silica fume, the strength of the section is increased gradually. Since silica fume is resistant to corrosion, concrete with silica fume is preferred to use in highway constructions, such as bridges and in rehabilitating existing structures.

In the US, about 2.5 million people are facing with respirable crystalline silica in their workplaces. In specific, there are about two million construction workers who drill and cut silica-containing materials such as concrete and stone, and 500,000 workers in operations such as brick manufacturing, foundries and hydraulic fracturing. In the various construction projects, most of the employers can limit harmful dust exposure by using equipment that is widely available, even just using water to keep dust from getting into the air would be beneficial and

${ }^{1}$ Silicafume (2018) http://www.silicafume.org/general-silicafume.html. 
ventilation system is also helpful to reduce the risk (OSHA 2016). In the construction, due to lack of sustainable restrictions, in many projects, the amount of silica is not monitored and that cause excessive amount of silica use in construction. With an excessive use of silica, human health is under danger. Uncontrolled use of such materials should be limited that will affect the current design procedures.

\section{Materials}

Concrete as a material in the industry is a mixture of Portland cement, water, and fine and coarse mineral aggregates, and sometimes various admixtures are also added in most of the cases. When all of the ingredients are mixed in the appropriate proportion, a complex chemical reaction occurs. This reaction is called as 'cement hydration', the process by concrete hardens and cures (Domone and Illston 2010).

In the present study in experimental set up, testing was planned to define the mechanic characteristic through various percentages in the existing design procedure. To investigate the effect of the ingredients in concrete, slag cement and fly ash were used. Slag cement and fly ash are explained below to define the mechanical characteristics of concrete.

\section{Slag Cement}

In the past few decades, the use of slag cement in the concrete industry has rapidly increased, since it has been considered an inexpensive material that enhances concrete properties. Before, slag cement was used in concrete industry in Europe. It had been found that the concrete structures made with slag cement show long-term high performance. In addition, using slag cement provides a durable concrete structure, which will reduce life-cycle cost (Slag Cement Association 2002). In addition, slag cement can be used either as supplementary material added to the concrete mix or as a mineral admixture blended with cement during the production of concrete for various constructions. Slag cement consists of silicates, aluminosilicates, and calcium-alumina-silicates (FHWA 2016, Lewis 1981). Slag cement is a non-metallic material that is produced as a waste material in iron production in the blast furnace. At a temperature at around $2732^{\circ} \mathrm{F}\left(1500^{\circ}\right.$ C), the slag is tapped from the blast furnace and is converted into different classifications depending on the cooling method. According to ASTM (C125-00a) "Standard Terminology Relating to Concrete and Concrete Aggregates," there are three typical types of slag cement: (a) Air-cooled blast-furnace slag, (b) Granulated blast-furnace slag, (c) Expanded blast-furnace slag (Lewis 1981).

Fly Ash

This material is a by-product that results from electrical power generations through the industry. Fly ash is basically a residue, carried by the generated gasses 
away from the burn out while the heavier unburned residue settles down in the furnace. The lighter residue characterized with cementitious properties is used with concrete. For most of the cases, the fly ash contains various percentages of calcium (Thomas 2007). According to ASTM C618-05, there are three types of fly ash: Class N, Class F, and Class C. Both Classes F and C are used in the concrete industry mostly.

\section{Water/Cement Ratio (W/C)}

Water content in the concrete mix has a significant impact on the UPV test values. Ye et al. (2001) conducted the UPV test on different concrete samples with different $(\mathrm{W} / \mathrm{C})$ ratios, as $0.4,0.45$, and 0.5 . They found that samples with lower W/C have higher UPV values comparing to other samples. The explanation of the difference is associated with various reasons, such as higher solid mass for those mixes and lower percentages of capillary pores. It is important to point out that the effect of Water and Cement ratio is almost impossible to understand at the early ages of concrete samples due to the higher amount of capillary pores (Panzera et al. 2011).

\section{The Size of Aggregate Particles}

The aggregate particles sizes and contents have a great impact on concrete properties. Therefore, the effect of aggregate should be considered during the UPV test. Higher aggregate sizes and amounts increase the UPV measurements. Also, a decrement in the compressive strength occurs due to the high aggregate amounts (Panzera et al. 2011). To get positive values from both tests, a high amount of attention should be paid during the mix design procedures.

\section{Methodology}

Materials generally contain crystalline silica which is not hazardous unless they are disturbed, generating small-sized particles that can get by people. For instance, in construction industry, blasting, cutting, chipping, drilling and grinding materials that contain silica can result in silica dust that is hazardous for people. In cement production, as a result of hydration is thermodynamically stable. Stability comes with high temperature as well. High temperature may create a stable, continuous and dependable environment and therefore, formation turns out a chemical reaction with high demand reactive material.

In addition to material characterization levels, it is also important to note that, hydration at high temperatures leads to the formation of highly crystalline silicate hydrates with more $\mathrm{Ca} / \mathrm{Si}$ ratio in the reactive material (Alp and Akin 2013, Bouzoubaa and Foo 2005). Type I Portland cements contain less than $0.1 \%$ crystalline silica by weight. In concrete, slag cement has been used either as supplementary material added with the concrete mix or as a mineral admixture blended with the Portland cement during its production (ASTM 2003, 2012). 
Based on the site investigations, it is observed that, slag cement consist of silicates, aluminosilicates, and calcium-alumina-silicates (FHWA 2016). By using fly ash in the concrete mix; concrete quality has enhanced and performance has increased. Comparing with the others, fly ash is the light unburned residue that is carried by the generated gasses away from the burning zone while the heavier unburned residue settles down in the bottom of the furnace. In many cases, it has a light characterization and the lighter residue characterized with cementitious properties is used with concrete. Based on the current practices in the construction, applications in construction, and experimental studies conducted in the various lab conditions, Fly ash contains various percentage of calcium (Thomas 2007, Barnett et al. 2006).

In this present paper, to reveal the silica effects on concrete, design setup has been discussed and investigated. By using an experimental design setup, the efficiency of crystalline silica in concrete samples has been investigated. In the experimental setup, various concrete samples were created and used in the research. As given in Figure 1, samples were created by using different Portland cement percentages and in different mixture proportion as detailed in Table 1 and Table 2. Table 1 summarizes the samples for detailing the characterization of the samples. In the research, for the testing process, UPV and Compression test equipment were used to record different percentages (Qasrawi and Marie 2003, Yang et al. 2011).

In the research, to understand the structural and mechanical response of the material, the samples were created based on the protocols. In the testing, components of each mix were weighted using an accurate electronic scale, and were later mixed together with 0.45 Water and Cement ratio using a concrete mixture equipment following the ASTM C192 procedures in Section 7.1.2 for mixing concrete. After finalizing each mix, the concrete cylinders were cast in plastic molds. To prevent the loss of moisture and to start the initial curing process the samples were stored in the room temperature for 24 hours. After the 24 hours, the concrete samples were demolded from the plastic molds and placed in a wider water tank for 28 curing days at a temperature between $70^{\circ} \mathrm{F}\left(21^{\circ} \mathrm{C}\right)$ to $77^{\circ} \mathrm{F}\left(25^{\circ}\right.$ C). With these constraints, materials have been prepared for the experimental investigation.

Table 1. Prepared Sample Sets used in the Tests

\begin{tabular}{|l|l|}
\hline Mix 1 (Sample A) & Control mix without Slag and Fly ash \\
\hline Mix 2 (Sample B) & Concrete mix with 50\% slag \\
\hline Mix 3 (Sample C) & Concrete mix with 25\% fly ash \\
\hline
\end{tabular}


Figure 1. Concrete Samples used in the Testing

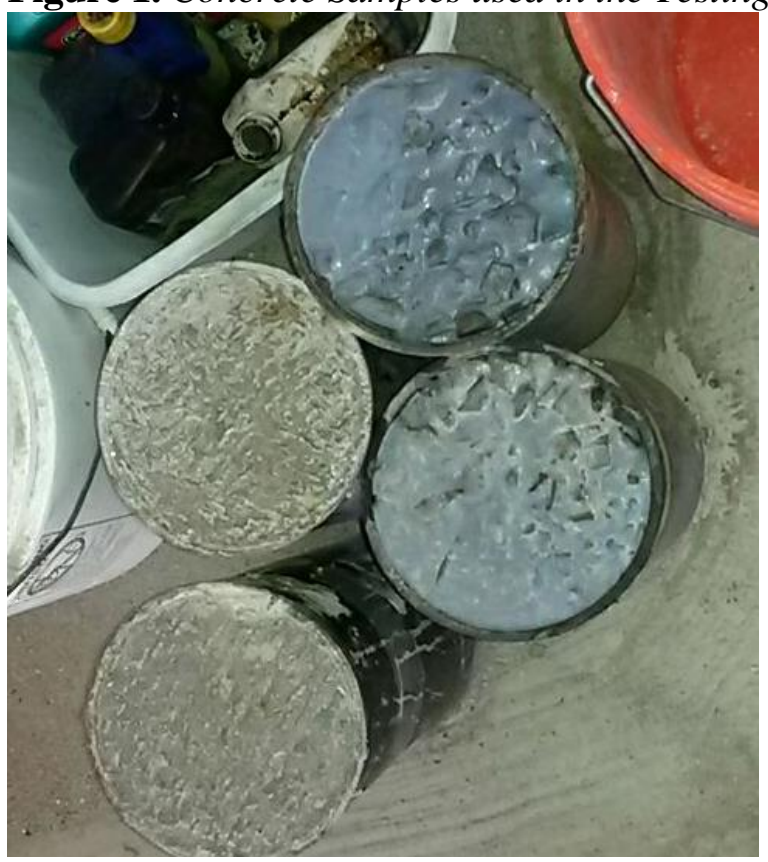

Table 2. Mixture Proportion of the Concrete Mixes

\begin{tabular}{|c|c|c|c|c|c|c|c|}
\hline \multirow{2}{*}{$\begin{array}{c}\text { Mix } \\
\text { Number }\end{array}$} & \multirow{2}{*}{$\begin{array}{l}\text { W/ } \\
\mathrm{C}\end{array}$} & \multirow{2}{*}{$\begin{array}{c}\text { Concrete } \\
\text { volume } \mathrm{ft}^{3}\end{array}$} & \multicolumn{5}{|c|}{ Mixture proportion $\mathrm{lb} / \mathrm{ft}^{3}\left(\mathrm{~kg} / \mathrm{m}^{2}\right)$} \\
\hline & & & Cement & $\begin{array}{c}\text { Slag } \\
\text { cement }\end{array}$ & Fly ash & $\begin{array}{c}\text { Fine } \\
\text { aggregate }\end{array}$ & $\begin{array}{c}\text { Coarse } \\
\text { aggregate }\end{array}$ \\
\hline 1 & $\begin{array}{c}0.4 \\
5\end{array}$ & 1 & $\begin{array}{l}21.43 \\
(343)\end{array}$ & 0 & 0 & $\begin{array}{l}42.85 \\
(686)\end{array}$ & $\begin{array}{c}85.72 \\
(1,373)\end{array}$ \\
\hline 2 & $\begin{array}{c}0.4 \\
5\end{array}$ & 1 & $\begin{array}{c}10.72 \\
(171.71)\end{array}$ & $\begin{array}{c}10.72 \\
(171.71)\end{array}$ & 0 & $\begin{array}{l}42.85 \\
(686)\end{array}$ & $\begin{array}{c}85.72 \\
(1,373)\end{array}$ \\
\hline 3 & $\begin{array}{c}0.4 \\
5\end{array}$ & 1 & $\begin{array}{l}16.1 \\
(258)\end{array}$ & 0 & $\begin{array}{c}5.36 \\
(85.85)\end{array}$ & $\begin{array}{l}42.85 \\
(686)\end{array}$ & $\begin{array}{c}85.72 \\
(1,373)\end{array}$ \\
\hline
\end{tabular}

\section{Experimental Testing}

In experimental testing, to determine the effect of crystalline silica on concrete samples, created samples were first put in the water for 28 days. 14 days after, they were removed from the water. In this sequence, samples were investigated by using UPV test as seen in Figure 2a. Afterwards, samples were cracked by using compression equipment up to $50 \mathrm{~K}$ loading as seen in Figure $2 \mathrm{~b}$. After cracking the samples, second UPV test was run. Then, the samples were put under the compression load until they got cracked as seen in Figure 2c. Cracking loads were recorded for the final stage of the research and the results were compared with each other. 
Figure 2. Testing Procedure

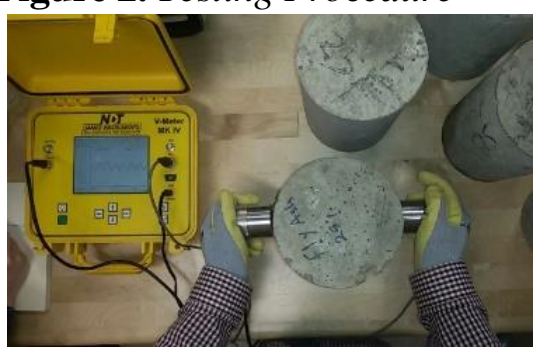

(a) UPV Test

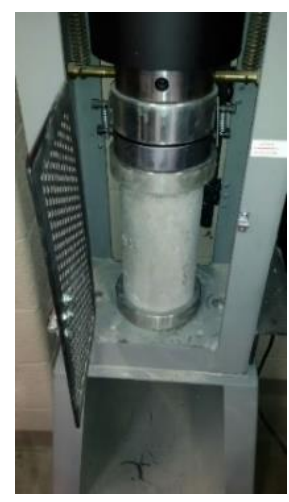

(b) Small Crack

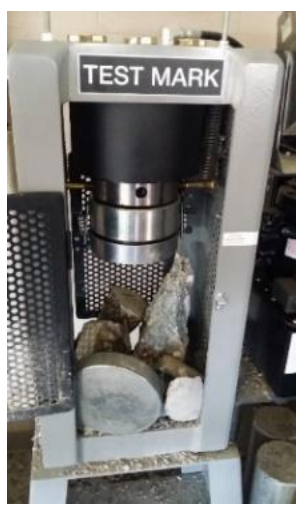

(c) Crash the Sample

The Ultrasonic Pulse Velocity (UPV) test is a non-destructive test that is used to evaluate the quality of different materials, such as concrete, steel, or wood. Historically, in 1920, the Russian scientist Sokolov was the first to use the UPV test to determine the defects in metal. In the 1940s, the pulse technique was first used on concrete by American scientists through a mechanicly generated pulse. They found that the velocity dependes on the elastic properties of the concrete. Later, electro-acoustic transducers were developed by the Canadian and British, which provided more accurate data (Hannachi and Guetteche 2014, Bungey and Millard 1996). The UPV test is a cost effective test, which can be employed easily and rapidly (Lawson et al. 2011). Test results will be used in the contentious evaluation of the concrete structures during their service life, which minimizes possibility of deficiencies in the concrete and also understand the effect on the concrete material (Lorenzi et al. 2007).

The UPV test essentially consists of an electrical pulse generator, two transducers (transmitting transducer and receiver transducer), calibration bar, and coupling gel (Hannachi, and Guetteche 2014, Bungey and Millard 1996). The gel should be placed between the transducers and the contact surface because "accuracy of transit time measurement can only be assured if good acoustic coupling between the transducer face and concrete surface can be achieved" (Sutan and Meganathan, 2003). The UPV test method is based on measuring the pulse speed and the transit time inside the concrete structures. The speed of waves depends on the elastic properties of the concrete. High-frequency sound waves travel through the concrete by using a transducer, which stays in contact with one of the concrete surface. The longitudinal speed of waves depends on the density of the concrete. A higher density means a faster wave speed. 
Figure 3. Ultrasonic Pulse Velocity Equipment
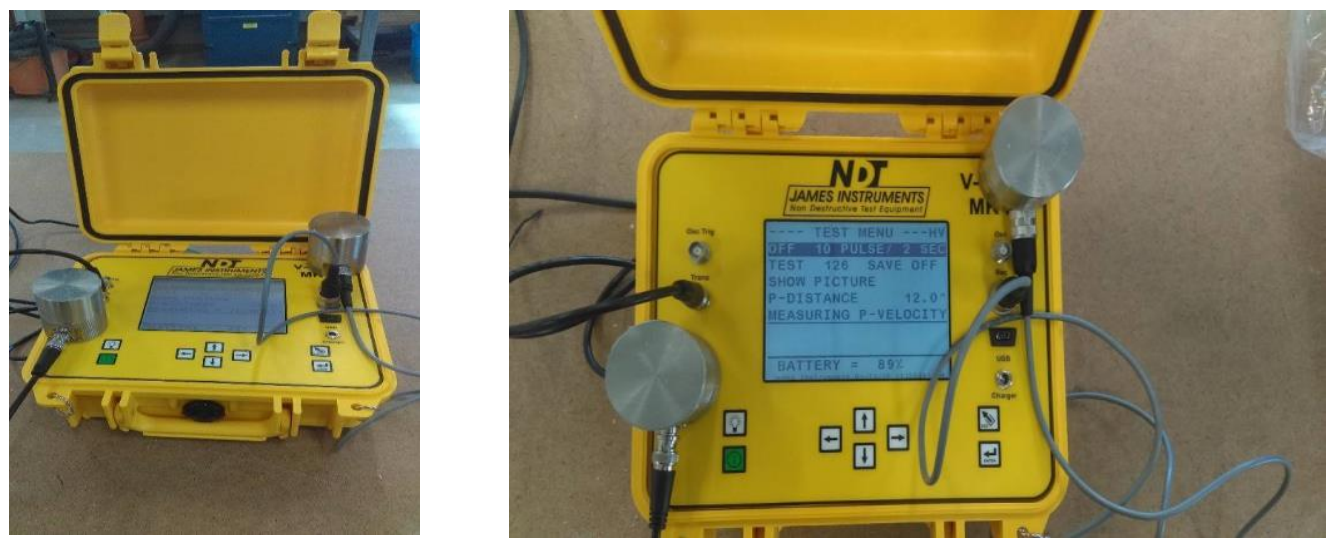

The other test carried out in the research is compression test. Compression equipment has been used to test the samples. Concrete strength has been determined for its strength as a structural material. A compression test is a common practice to define the mechanical characteristics of concrete samples. The maximum recorded force in the test through the equipment is the compression strength of that particular sample.

The concrete compression test equipment that was used in this research is CM-2500 series manufactured by Test Mark industries. This equipment has a loading capacity ranging between 2,500-250,000 lbs. (11-1112 kN); it meets with the ASTM C-39 and AASHTO-22 for testing concrete specimens. The machine is controlled by valve and hydraulic pump; the digital reading screen is placed on the right side of the test machine. This equipment has load accuracy $\pm 0.5 \%$ and supplied with heavy duty pressure cylinders. The CM-2500 has an auto shutdown when the piston exceeds its maximum stroke. Besides, an electronic safety feature turns the hydraulic pump off at sample failure or when the equipment reaches its maximum capacity. During the specimen test, the rate of loading was determined according to the ASTM-39 standard, which was $37 \pm 7$ psi $(255 \pm 48 \mathrm{kPa})$ per second.

In the research, two main experimental set up were established. In these two experiments, samples were tested. Followed experimental steps are given in Table 3. Procedure is followed according to literature review (Bungey and Millard 1996, Wang et al. 2006, Ye et al. 2001). Samples were placed in a water tank for curing for 28 days. The UPV test was performed on each specimen following the ASTM C597-02 Standards for three different positions on cylinders' axial direction; the specimens were subjected to $(2.0 \mathrm{MHz})$ sound waves during the test. The benefit of documenting the UPV values at the beginning was to indicate the initial pulse velocity value, which gives an idea about the status of the concrete cylinders' structure before applying any compression load. In addition, these values were used as base values during the evaluating process of the self-healing capability and in calculating the damage level for each cylinder. Right after measuring the initial UPV value, a compression load was applied on concrete cylinders approximately $50,000 \mathrm{lb}$. (1,500 Psi) [10.34 Mpa]. The point of this step was not to measure the ultimate compressive strength of the specimens but to force each sample to 
generate internal cracks within its structure. On the same day, the UPV test was performed again for the all samples to measure the changes in pulse velocity values in comparison with the measured initial values. There were some changes in UPV, which indicated that the specimen structures were damaged due to the load application. Then, the saturated samples were placed back in the water tank, while the frozen samples were returned to the freezer for 30 days. At this point, the first stage of the testing procedures was completed.

After the 30 days, the second stage was started, which was to remove the samples from the water and freezer to perform the next UPV test. Then, the samples were placed back in water and freezer for another 30 days. After 60 days from the first pulse velocity evaluation, the final UPV test was executed for all concrete samples. The purpose of applying the UPV test in different periods was to build a relationship between the healing degree and rate with time for each concrete mix. At the end of the experiential investigation, the samples were crushed by using the compression testing equipment by applying an axial compression load until the failure point.

Table 3. Experimental Steps

\begin{tabular}{|c|l|}
\hline Steps & Action \\
\hline $\mathbf{1}$ & Poured concrete into molds \\
\hline $\mathbf{2}$ & After waiting 48 hours, put in water for 28 days \\
\hline $\mathbf{3}$ & Removed from water to dry for 14 days \\
\hline $\mathbf{4}$ & $\begin{array}{l}\text { Run the UPV test for the first time: calculating the time and velocity (10 } \\
\text { tests for each sample). }\end{array}$ \\
\hline $\mathbf{5}$ & Create small crack inside samples up to 50K loading \\
\hline $\mathbf{6}$ & Run the UPV test for the second time. \\
\hline $\mathbf{7}$ & Put the sample under the compression load until it crashed. \\
\hline
\end{tabular}

\section{Research Findings}

In the present research, samples were tested by using the Ultrasonic Pulse Velocity (UPV) test and Compression Test equipment to investigate to increase the strength of concrete. As a result, UPV test and compression test results are given in charts for comparison. Figure 4 gives the comparison of compression test results. Table 4 gives the UPV test results. Two different sets of UPV tests results are summarized. These results were recorded with the same order of experimental steps as given in Figure 5. 
Vol. 6, No. 2 Korkmaz \& Ashur: Experimental Investigation of Crystalline...

Figure 4. Compression Test Results

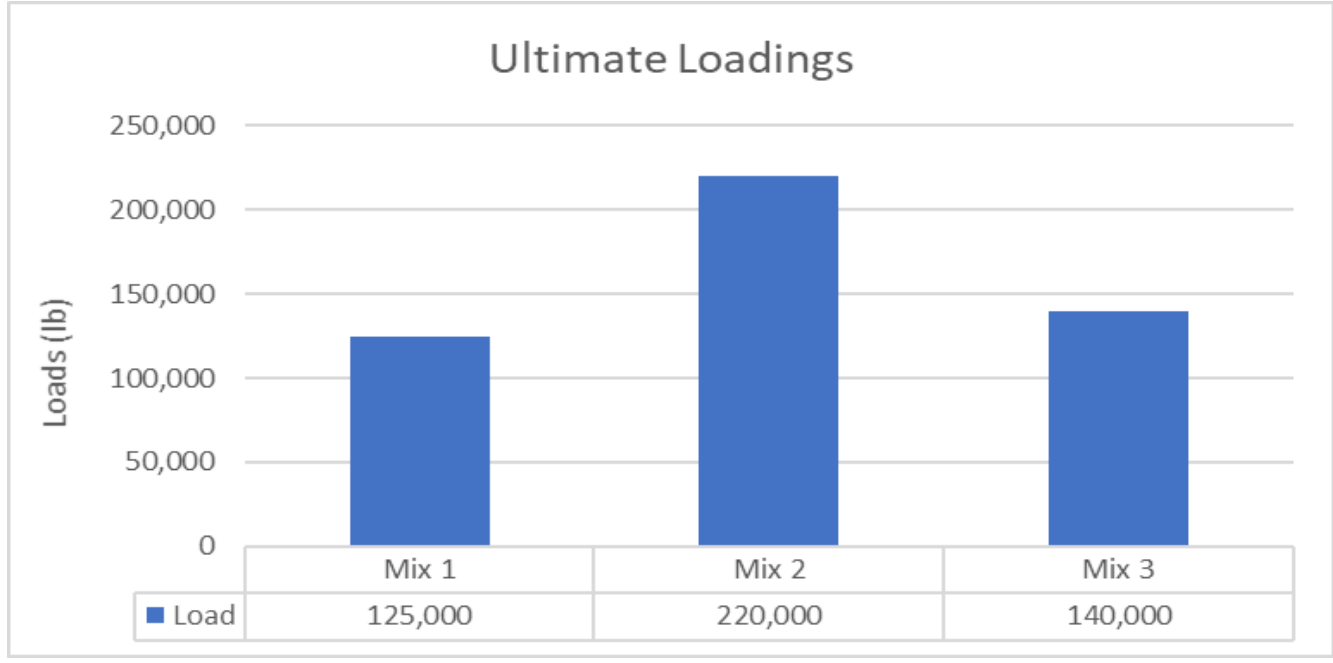

Figure 5. UPV Test Results

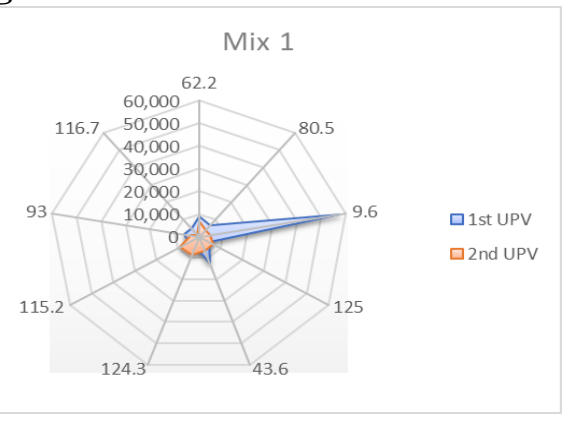

a) Mix 1 UPV Distribution

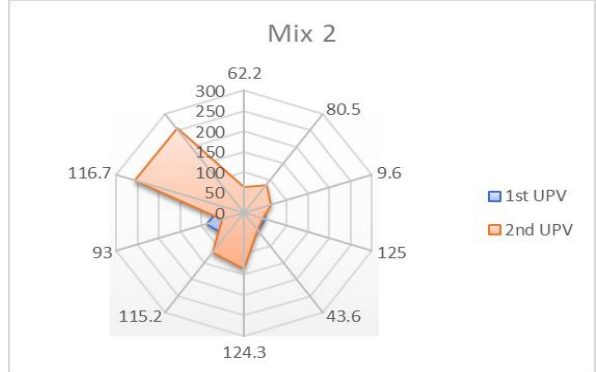

b) Mix 2 UPV Distribution

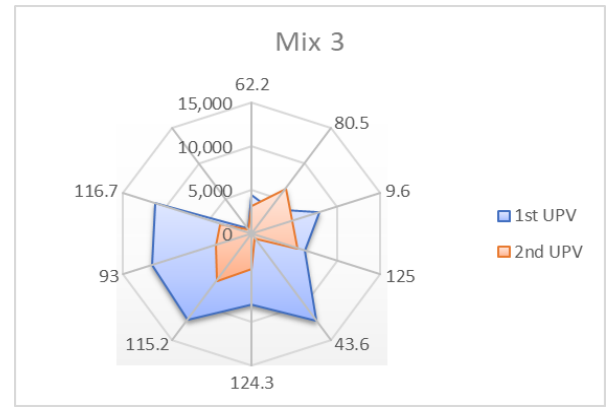

c) Mix 3 UPV Distribution

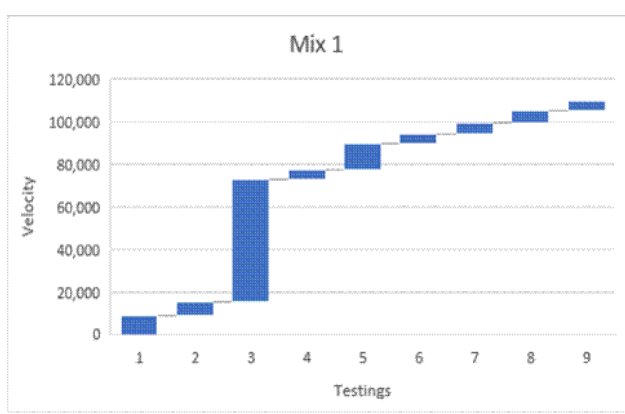

a) Mix 1 UPV Test Results

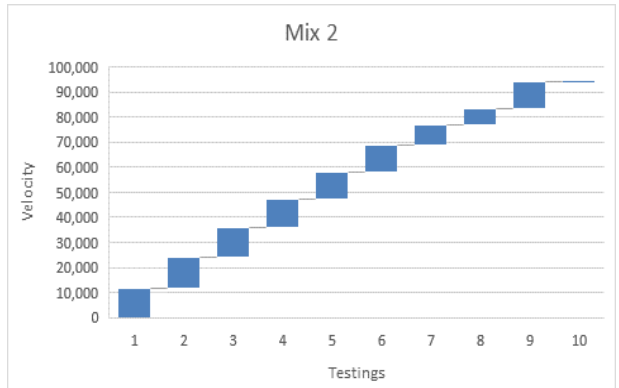

b) Mix 2 UPV Test Results

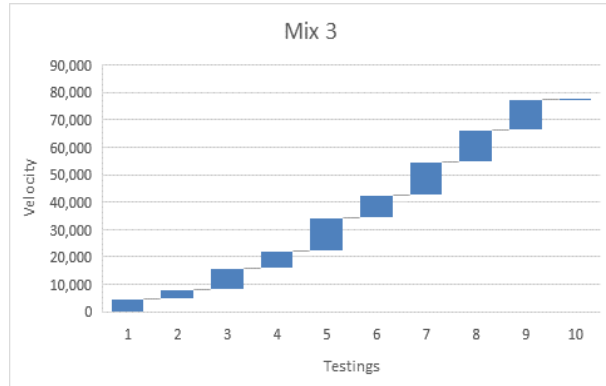

c) Mix 3 UPV Test Results 
Table 4. UPV Test Results

\begin{tabular}{|c|c|c|c|c|}
\hline \multirow{11}{*}{ Mix 1} & Mix 1 & $1^{\text {st }}$ UPV & Mix 1 & $2^{\text {nd }}$ UPV \\
\hline & TIME & VELOCITY & TIME & VELOCITY \\
\hline & 62 & 8,842 & 81 & 6,740 \\
\hline & 80 & 6,832 & 137 & 3,994 \\
\hline & 9 & 57,292 & 125 & 4,404 \\
\hline & 125 & 4,416 & 85 & 6,433 \\
\hline & 43 & 12,557 & 82 & 6,651 \\
\hline & 124 & 4,425 & 66 & 8,271 \\
\hline & 115 & 4,774 & 63 & 8,648 \\
\hline & 93 & 5,926 & 154 & 3,560 \\
\hline & 116 & 4,712 & 474 & 1,158 \\
\hline \multirow{12}{*}{ Mix 2} & Mix 2 & $1^{\text {st }}$ UPV & $\operatorname{Mix} 2$ & $2^{\text {nd }}$ UPV \\
\hline & TIME & VELOCITY & TIME & VELOCITY \\
\hline & 46 & 11,752 & 62 & 8,748 \\
\hline & 45 & 12,222 & 83 & 6,555 \\
\hline & 46 & 11,905 & 63 & 8,703 \\
\hline & 48 & 11,364 & 44 & 12,443 \\
\hline & 52 & 10,577 & 52 & 10,577 \\
\hline & 49 & 11,066 & 136 & 4,041 \\
\hline & 68 & 8,076 & 119 & 4,591 \\
\hline & 87 & 6,271 & 51 & 10,618 \\
\hline & 51 & 10,597 & 256 & 2,142 \\
\hline & 67 & 819 & 256 & 2,151 \\
\hline \multirow{12}{*}{$\operatorname{Mix} 3$} & $\operatorname{Mix} 3$ & $1^{\text {st }}$ UPV & Mix 3 & $2^{\text {nd }}$ UPV \\
\hline & TIME & VELOCITY & TIME & VELOCITY \\
\hline & 122 & 4,508 & 176 & 3,125 \\
\hline & 159 & 3,448 & 86 & 6,373 \\
\hline & 69 & 7,902 & 117 & 4,677 \\
\hline & 88 & 6,201 & 102 & 5,345 \\
\hline & 45 & 12,222 & 922 & 596 \\
\hline & 68 & 8,088 & 135 & 4,065 \\
\hline & 45 & 12,141 & 83 & 6,611 \\
\hline & 47 & 11,579 & 130 & 4,211 \\
\hline & 48 & 11,247 & 148 & 3,699 \\
\hline & 768 & 715 & 909 & 605 \\
\hline
\end{tabular}


Different mixes were given and time vs velocity values are indicated in Table 4 for two sets of UPV tests. According to the results, mix 2 values are higher comparing to mix 1 and mix 3. Mix 1 and mix 3 values are closed to each other. Mix 2 has slag in the mix. In mix 3, there is fly ash in the mixture. Both of them have similar silica percentages in the mixture. Therefore, it can be seen through this research, strength is not selective parameter for silica fume percentage in the concrete.

\section{Conclusions}

The present paper investigates impacts of crystalline silica in concrete by changing concrete mixture proportions through mechanical properties. Effects of crystalline silica on different cementitious and polymeric materials, such as slag cement and fly ash have been investigated and obtained results are given. The research methodology consisted of two different experimental tests as, the ultrasonic pulse velocity (UPV) and compression test. As seen in Figure 4, resistance of Mix 2 is the highest with 220,000lb ultimate loading. Mix 3 and Mix 1 are at similar ranges. Based on these results, Mix 2 values are the ones that can be used in the mix design procedure with their higher values. The UPV test results were given in Figure 5. According to results from UPV and compression tests, Mix 2 has higher values.

Based on the investigation carried out through the research, Silica affects the concrete behavior. With existing design procedures and protocols, silica use is at an excessive level and should be controlled in the upcoming regulations. With the new restrictions by OSHA, it is obvious that the silica use will be limited in the concrete. Therefore, it is important to investigate the structural and mechanic characteristics for concrete using different ingredients and additives. With different material use, characteristics of concrete will be different.

With increased health concerns and awareness in the wider spectrum in recent years, industrial byproducts become critical to understand in concrete and its applications. One such by-product is silica, which is a byproduct of the silicon and ferrosilicon industry. Silica is one of the main and critical materials used in high strength high performance concrete production and its derivatives. In recent years, there have been various research work completed to cover this issue in the existing frame. Some of Department of Transportations (DOT)'s started working on evaluating effects of silica in concrete in physical, chemical properties of it, and its reaction and resistance mechanism.

Even it is still controversial, crystalline silica has a possible cause of lung cancer or some other diseases and therefore, it is important to limit the use of silica in the concrete industry. Millions are interested in this decision. In a short run, it is important to define the effects of silica in strength and characteristics. That will be extended in the long run. Department of Transportations (DOT)'s will change or revise their design procedures. With OSHA's new regulation, in construction industry, a game changing regulation will be effective in next years. To make right 
decisions in the concrete design, it is important to get accurate data and definitions for concrete characteristics.

Figure 4 gives the comparison of compression test results. Within the results, Mix 2 has the highest value. With the strength characteristics of concrete samples, the max strength values were determined. In Figure 5, UPV test values are given below. For each mix, UPV change was sketched for three different cases. The coverage and change are given in the diagrams. Characteristic definition can be based on these charts and it would be possible to see the change with different design procedures. Distribution gives the core part for the stress distribution in two different areas. So, the main areas for a stress distribution are demonstrated in Figure 4. In the chart, the change is given with the change in the UPV value changes. In addition to the graphs, Table 4 is summarizing the UPV test results with their values for three different mix set up.

This research is representing the results of the carried out experiments. The sample number should be increased and the results should be increased with more samples and more alternatives. Various types of concrete ingredients should be included to the result to give better coverage in the design procedures.

\section{References}

Alp B, Akin S (2013) Utilization of Supplementary Cementitious Materials in Geothermal Well Cementing. $38^{\text {th }}$ Workshop on Geothermal Reservoir Engineering Stanford University, Stanford, California, February 11-13, 2013.

ACI 224 - American Concrete Institute (2007) Cracking, and American Concrete Institute. Causes, Evaluation, and Repair of Cracks in Concrete Structures. Farmington Hills, MI.: American Concrete Institute.

ACI 301-10 - American Concrete Institute (2010) Specifications for Structural Concrete. Retrieved from https://bit.ly/1P15jID.

ASTM - American Society for Testing and Materials (2003) Standard Method of Test for Compressive Strength of Cylindrical Concrete Specimens. C 39/C 39M - 03. West Conshohocken, PA.

ASTM - American Society for Testing and Materials (2012) Standard Practice for Making and Curing Concrete Test Specimens in the Laboratory. C192/C192M-12a. West Conshohocken, Pa.

Barnett SJ, Soutsos MN, Millard SG, Bungey JH (2006) Strength Development of Mortars Containing Ground Granulated Blast-Furnace Slag: Effect of Curing Temperature and Determination of Apparent Activation Energies. Cement and Concrete Research 36(3): 434-440.

Bouzoubaâ N, Foo S (2005) Use of Fly Ash and Slag in Concrete: A Best Practice Guide. Government of Canada Action Plan 2000 on Climate Change.

Bungey JH, Millard SG (1996) Testing of Concrete in Structures. $3^{\text {rd }}$ Edition. London; New York: Blackie Academic and Professional.

Domone P, Illston J (2010) Construction Materials: Their Nature and Behavior. $4^{\text {th }}$ Edition. USA and Canada: Spon Press.

FHWA - Federal Highway Administration Research and Technology (2016) User Guidelines for Waste and Byproduct Materials in Pavement Construction. Retrieved from https://bit.ly/2TFB6d5. 
Hannachi S, Guetteche MN (2014) Review of the Ultrasonic Pulse Velocity Evaluating Concrete Compressive Strength on Site. Scientific Cooperations International Workshops on Engineering Branches, 8-9 August 2014, Koc University, Istanbul, Turkey. Retrieved from https://bit.ly/2O3xgoJ.

Lawson I, Danso KA, Odoi HC, Adjei CA, Quashie FK, Mumuni II, Ibrahim IS (2011) Non-Destructive Evaluation of Concrete using Ultrasonic Pulse Velocity. Research Journal of Applied Sciences, Engineering and Technology 3(6): 499-504.

Lewis DW (1981) History of Slag Cements, 1-9. National Slag Association. Retrieved from https://bit.ly/2EZ3kWF.

Lorenzi A, Tisbierek FT, Silva LCP (2007) Ultrasonic Pulse Velocity Análysis in Concrete Specimens. IV Conferencia Panamericana de End, Buenos Aires. Retrieved from https://bit.ly/2NSFLX0.

OSHA - Occupational Safety and Health Administration (2016) US Labor Department Announces Final Rule to Improve U.S. Workers' Protection from the Dangers of 'Respirable' Silica Dust. Retrieved from https://bit.ly/2yFj6ot.

OSHA - Occupational Safety and Health Administration (2018a) Crystalline Silica Exposure Health Hazard Information. Retrieved from https://bit.ly/1kCJRb8.

OSHA - Occupational Safety and Health Administration (2018b) Silica, Crystalline. Retrieved from https://www.osha.gov/dsg/topics/silicacrystalline/.

Panzera TH, Strecker K, Miranda JS, Christoforo AL, Borges PHR (2011) Cement Steatite Composites Reinforced with Carbon Fibres: An Alternative for Restoration of Brazilian Historical Buildings. Materials Research 14(1): 118-123.

Qasrawi HY, Marie IA (2003) The Use of USPV to Anticipate Failure in Concrete under Compression. Cement and Concrete Research 33(12): 2017-2021.

Slag Cement Association (2002) Slag Cement in Concrete. Retrieved from http://www. slagcement.org/pdf/no1\%20slag\%20cement.pdf.

Sutan NM, Meganathan M (2003) A Comparison between Direct and Indirect Method of Ultrasonic Pulse Velocity in Detecting Concrete Defects. Russian Journal of Nondestructive Testing 8(5): 1-9. Retrieved from https://bit.ly/2HvOl9v.

Thomas M (2007) Optimizing the Use of Fly Ash in Concrete. Portland Cement Association. https://bit.ly/2OaWodr.

Wang K, Schaefer VR, Kevern JT, Suleiman MT (2006) Development of Mix Proportion for Functional and Durable Pervious Concrete. Proceedings of the 2006 NRMCA Concrete Technology Forum, Focus on Pervious Concrete.

Yang Z, Hollar J, He X, Shi X (2011) A Self-Healing Cementitious Composite using Oil Core/Silica Gel Shell Microcapsules. Cement and Concrete Composites 33(4): 506512. Retrieved from https://bit.ly/2FaEIRE.

Ye G, Van Breugel K, Fraaij AL (2001) Experimental Study on Ultrasonic Pulse Velocity Evaluation of the Microstructure. TU Delft Institutional Repository, Delft University of Technology. 